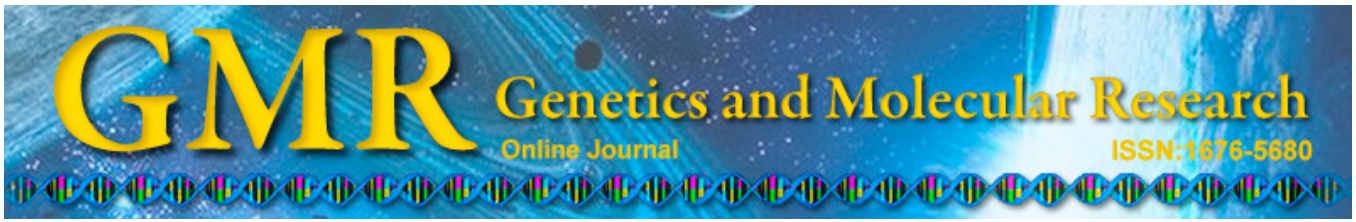

\title{
Identification of Pseudomonas syringae pv. actinidiae strains causing bacterial canker of kiwifruit in the Anhui Province of China, and determination of their streptomycin sensitivities
}

\author{
X. Yang ${ }^{1,5,6 *}$, X.-K. Yi ${ }^{2,3 *}$, Y. Chen ${ }^{1,5,6}$, A.-F. Zhang ${ }^{1,5,6}$, J.-Y. Zhang ${ }^{2,3}$, \\ Z.-H. Gao ${ }^{2,3}$, Y.-J. $\mathrm{Qi}^{2,3}$ and Y.-L. $\mathrm{Xu}^{3,4}$ \\ ${ }^{1}$ Institute of Plant Protection and Agro-Products Safety, \\ Anhui Academy of Agricultural Sciences, Hefei, China \\ ${ }^{2}$ Insitute of Horticulture, Anhui Academy of Agricultural Sciences, Hefei, China \\ ${ }^{3}$ Key Laboratory of Genetic Improvement and Ecophysiology of Horticultural \\ Crops, Anhui Province, Hefei, China \\ ${ }^{4}$ Anhui Academy of Agricultural Sciences, Hefei, China \\ ${ }^{5}$ Laboratory of Quality \& Safety Risk Assessment for Agro-Products (Hefei), \\ Ministry of Agriculture, Hefei, China \\ ${ }^{6}$ Scientific Observing and Experimental Station of Crop Pests in Hefei, \\ Ministry of Agriculture, Hefei, China \\ *These authors contributed equally to this study. \\ Corresponding author: Y.-L. Xu \\ E-mail: yiliuxu@163.com
}

Genet. Mol. Res. 14 (3): 8201-8210 (2015)

Received August 8, 2014

Accepted January 29, 2015

Published July 27, 2015

DOI http://dx.doi.org/10.4238/2015.July.27.7

ABSTRACT. Bacterial canker, caused by Pseudomonas syringae pv. actinidiae, is one of the most severe diseases of kiwifruit. It has become an international pandemic and threatens the sustainable development of kiwifruit production in all main kiwi-growing regions worldwide. Streptomycin has been the major bactericide for the control of kiwifruit canker, especially in Anhui Province, one of the main kiwifruit 
production regions in China. However, until now, no studies on the baseline sensitivity to streptomycin of field isolates of $P$. syringae $\mathrm{pv}$. actinidiae from China have been available. During 2012-2013, a total of 102 single-colony $P$. syringae pv. actinidiae strains were isolated: $36,12,13,26$, and 15 strains from Yuexi, Jinzhai, Huoshan, Qianshan, and Taihu counties, respectively. All strains were confirmed by production of a 280-bp fragment using the specific primers PsaF1/R2 upon polymerase chain reaction amplification, followed by an assay for confirmation of pathogenicity to fulfill Koch's postulates. In this study, the streptomycin sensitivity of the 102 isolated strains was determined. The half-maximal effective concentration values for inhibition of growth by streptomycin were $0.03-0.42 \mu \mathrm{g} / \mathrm{mL}$ (average $0.12 \pm 0.06$ $\mu \mathrm{g} / \mathrm{mL}$ ). The baseline sensitivity curve was unimodal, representing range-of-variation factors of 14.0. No resistant subpopulation was identified among the strains used in the study. Thus, these sensitivity data could be used as a baseline for monitoring the shift in sensitivity of $P$. syringae pv. actinidiae populations to streptomycin in Anhui Province. Continuous resistance monitoring should be carried out, as streptomycin is an at-risk bactericide agent.

Key words: Pseudomonas syringae pv. actinidiae; Specific PCR; Streptomycin; Baseline sensitivity; Detection of kiwifruit bacterial canker

\section{INTRODUCTION}

Pseudomonas syringae pv. actinidiae is the causal agent of kiwifruit canker, which causes leaf spots, dieback, and canker symptoms on kiwifruit (Scortichini, 1994; Chapman et al., 2012), and has been shown to damage kiwifruit production worldwide (Chapman et al., 2012). According to previous reports, this disease was first reported in Asian countries such as Japan (Takikawa et al., 1989), the Hunan Province of China (Fang et al., 1990), and Korea (Koh et al., 1994), and was subsequently identified in European countries such as Italy (Ferrante and Scortichini, 2009), Portugal (Balestra et al., 2010), France (Vanneste et al., 2011a), Spain (Abelleira et al., 2011), Switzerland (EPPO, 2011), and Turkey (Bastas and Karakaya, 2012). Historically considered a minor disease, $P$. syringae pv. actinidiae rarely caused severe damage to kiwifruit until 2008, when a large outbreak occurred in Italy, and severe infections continue to spread to other countries (Mazzaglia et al., 2011; Chapman et al., 2012; Balestra et al., 2009, 2013; Vanneste et al., 2013). In Italy, the bacterium has been shown to cause severe disease symptoms, including leaf wilting; twig or cane dieback; cankers on canes, leaders, and trunks; plant wilting; and the production of an oozing red or white exudate (Ferrante and Scortichini, 2010; Bull et al., 2011). After just a few years, this disease has become an international pandemic and is threatening the sustainable development of kiwifruit production in all the main kiwi-growing regions worldwide. Under favorable conditions for an epidemic of this disease, $P$. syringae pv. actinidiae can destroy an entire kiwi tree within a few months.

The disease is very difficult to control because of its extensive distribution, severe effects, broad host base, and high pathogenicity, resulting in serious yield and economic losses. As the major kiwifruit cultivars Actinidia deliciosa and Actinidia chinensis are both very sus- 
ceptible to this disease, $P$. syringae pv. actinidiae can affect all of the commercial cultivars of kiwifruit, such as the green-fleshed kiwifruits A. deliciosa 'Hayward' and 'Summer Kiwi', and the yellow-fleshed kiwifruits A. chinensis 'Jin Tao', 'Hort16A', and 'Soreli'. This also leads to limited opportunities to screen for new resources conferring resistance to this disease. Furthermore, because little is known about natural hosts, the infection process, and colonization sites of the pathogen, it is still not clear what the pathogenic mechanism is, resulting in high costs and poor efficiency of control. Therefore, the application of bactericides becomes an indispensable complementary tool, especially for regions planting susceptible cultivars (Xu et al., 2010). During a survey, we found that most kiwifruit growers sprayed bactericides to control this disease. Streptomycin is the most commonly used bactericide used to control kiwifruit bacterial canker in China (Xu et al., 2010). Streptomycin is an aminoglycoside antibiotic and has been widely used in the treatment of human and animal bacterial diseases (Sundin and Bender, 1993). Since it was introduced for crop protection in 1955, streptomycin has been the major antibiotic for controlling plant diseases caused by Gram-negative bacteria such as those causing fire blight (Erwinia amylovora), soft rot diseases of cut flowers and potato seed pieces (Pectobacterium spp formerly Erwinia spp), fruit-spotting or blossom-blast symptoms on apple, pear, and related landscape trees (P. syringae), and bacterial spot of pepper and tomato (Xanthomonas campestris pv. vesicatoria) (McManus et al., 2002). China is one of the main kiwifruit-production regions worldwide and canker has been the most effective disease limiting production of kiwifruit in this country. However, until now, no studies on the baseline sensitivity to streptomycin of field isolates of $P$. syringae pv. actinidiae from China have been available. This provides an opportunity to study the baseline sensitivity of $P$. syringae pv. actinidiae strains to streptomycin, although it has already been used for control of this disease in China.

Establishment of the baseline sensitivity is a useful tool for monitoring sensitivity shifts and effectiveness of resistance management strategies, and is one of the major tasks undertaken by scientists working in the chemical control of pests, forming a significant part of the registration process for pesticides (Russell, 2004). The objectives of this study were to: i) identify the pathogen by polymerase chain reaction (PCR) amplification of the $16 \mathrm{~S}$ rDNA region, and ii) establish the baseline sensitivity to streptomycin of $P$. syringae pv. actinidiae strains that were never exposed to this bactericide.

\section{MATERIAL AND METHODS}

\section{Collection of plant samples and isolation of $P$. syringae pv. actinidiae}

The leaves, twigs, and canes of kiwifruit with symptoms of bacterial canker were collected from the major growing regions for kiwifruit of Anhui Province, China, including Yuexi, Jinzhai, Huoshan, Qianshan, and Taihu counties during 2012-2013.

Bacterial strains were isolated from leaves, twigs, or canes using the following methods: leaf samples were isolated as described by Vanneste et al. (2011b) with slight modification. Briefly, $100 \mu \mathrm{L}$ washing solution was obtained by vigorously rubbing each leaf for 2 $\mathrm{min}$ in $10 \mathrm{~mL}$ sterile distilled water and plated on nutrient agar (NA) medium containing $1 \%$ cycloheximide at $5 \mathrm{~mL} / \mathrm{L}$. NA medium consisted of $5 \mathrm{~g}$ polypeptone, $1 \mathrm{~g}$ yeast powder, $3 \mathrm{~g}$ beef extract, $10 \mathrm{~g}$ sucrose, and $17 \mathrm{~g} / \mathrm{L}$ agar, with the $\mathrm{pH}$ adjusted to 7.0 with $1 \mathrm{M} \mathrm{NaOH}$. Small sections of twig or cane tissue were teased out in sterile water and the suspension was spread 
onto NA plates supplemented with cycloheximide. After $28 \mathrm{~h}$ incubation at $28^{\circ} \mathrm{C}$, P. syringae pv. actinidiae-like colonies were purified by picking up single colonies. One single-colony isolate of $P$. syringae pv. actinidiae was obtained from each leaf, twig, or cane, yielding a total of 102 single-colony strains (Table 1). A standard P. syringae pv. actinidiae strain was kindly provided by Prof. Gen-Jia Tan (Anhui Agricultural University), which was used as a positive control. Bacterium identification was based on colony morphology and was confirmed by sequencing the $16 \mathrm{~S}$ rDNA and by a pathogenicity assay.

\section{Identification of $P$. syringae pv. actinidiae by PCR}

Total DNA from each of the collected strains was isolated according to Zhang et al. (2011) with slight modifications. Briefly, after the bacteria were grown in NB (NA minus agar) at $28^{\circ} \mathrm{C}$ for $24 \mathrm{~h}$, a bacterial suspension aliquot $(1.5 \mathrm{~mL})$ was centrifuged at $12,000 \mathrm{~g}$ for $10 \mathrm{~min}$. The pellet was resuspended in $567 \mu \mathrm{L}$ TE buffer [10 mM Tris-HCl, 1 $\mathrm{mM}$ ethylenediaminetetraacetic acid (EDTA), $\mathrm{pH}$ 8.0]. Proteinase $\mathrm{K}$ and sodium dodecyl sulfate were added to final concentrations of $100 \mu \mathrm{g} / \mathrm{mL}$ and $5 \mathrm{~g} / \mathrm{L}$, respectively. After incubation for $1 \mathrm{~h}$ at $37^{\circ} \mathrm{C}$, sodium chloride and hexadecyltrimethylammonium bromide were added to each preparation to final concentrations of $0.7 \mathrm{M}$ and $10 \mathrm{~g} / \mathrm{L}$, respectively. The preparations were incubated at $65^{\circ} \mathrm{C}$ for $10 \mathrm{~min}$, and DNA was extracted with chloroform/isoamyl alcohol (24:1 by volume). Samples were shaken for $10 \mathrm{~min}$ and centrifuged at $12,000 \mathrm{~g}$ for $20 \mathrm{~min}$. DNA was re-extracted with phenol/chloroform/isoamyl alcohol (25:24:1 by volume) and centrifuged as described above. DNA was precipitated by adding 0.6 volumes isopropanol and incubating at $-20^{\circ} \mathrm{C}$ for $30 \mathrm{~min}$. Samples were centrifuged at $12,000 \mathrm{~g}$ for $20 \mathrm{~min}$, and the pellets were washed with $1 \mathrm{~mL} 70 \%$ ethanol and centrifuged again. The DNA was dried at room temperature, and the pellet was then re-dissolved in 50 $\mu \mathrm{L}$ sterilized ultrapure water and stored at $-20^{\circ} \mathrm{C}$.

Based on the conserved 16S-23S rDNA intertranscribed spacer (ITS) region of P. syringae pv. actinidiae, the PCR primers PsaF1 5' - TTT TGC TTT GCA CAC CCG ATT TT - 3' and PsaR2 5' - CAC GCA CCC TTC AAT CAG GAT G - 3' were used for specific amplification of the target fragment from P. syringae pv. actinidiae by PCR, according to previous report (Rees-George et al., 2010). PCR mixtures contained total DNA, $1.5 \mathrm{mM} \mathrm{MgCl}_{2}, 200 \mu \mathrm{M}$ of each dNTP, and 2.5 units Taq DNA polymerase. PCRs were performed in a DNA Engine System PT-200 (Bio-Rad, Watertown, MA, USA) programmed for $2.5 \mathrm{~min}$ at $94^{\circ} \mathrm{C}$, followed by 30 cycles of $0.5 \mathrm{~min}$ at $94^{\circ} \mathrm{C}, 1 \mathrm{~min}$ at $52^{\circ} \mathrm{C}$, $1.5 \mathrm{~min}$ at $72^{\circ} \mathrm{C}$, a final extension for $8.5 \mathrm{~min}$ at $72^{\circ} \mathrm{C}$, and a $4^{\circ} \mathrm{C}$ hold. PCR products were separated by electrophoresis on $1.5 \%$ agarose gels in $40 \mathrm{mM}$ Tris-acetate, $\mathrm{pH} 8.0$, and 1 mM EDTA (TAE) buffer. The PCR products were purified using a DNA Gel Extraction Kit (AxyPrep ${ }^{\mathrm{TM}}$, Corning, Hangzhou, China) according to manufacturer instructions, and sequenced by Shanghai Sangon Biological Engineering Technology \& Services Co., Ltd. (Shanghai, China).

\section{Pathogenicity assay}

A suspension containing the bacterial strain to be tested at approximately $10^{9} \mathrm{CFU} /$ $\mathrm{mL}$ was made in water from colonies freshly grown on NA plates. These suspensions were sprayed on the abaxial side of unwounded leaves. At least six 3 to 4 -month-old seedlings were 
used per assay. All fully developed leaves were inoculated. When the assays were carried out on 1-year-old A. chinensis 'Jintao' plants, five plants per treatment were used. The plants were kept at an average temperature of approximately $20^{\circ} \mathrm{C}$ in plastic chambers to maintain the relative humidity. After 14 or 21 days, the necrotic spots on each leaf were observed and the $P$. syringae pv. actinidiae strain was re-isolated as described above.

\section{Baseline streptomycin sensitivity of $P$. syringae pv. actinidiae strains from Anhui Province}

The sensitivities of $P$. syringae pv. actinidiae strains to streptomycin were determined based on the in vitro inhibition of bacterial growth in NB medium (Li et al., 2006; $\mathrm{Xu}$ et al., 2010). Briefly, each of the bacterial strains was grown in $\mathrm{NB}$ at $28^{\circ} \mathrm{C}$ until the late logarithmic growth phase, and then the suspension was diluted to a density of approximately $10^{7} \mathrm{CFU} / \mathrm{mL}$. Aliquots $(100 \mu \mathrm{L})$ of the suspension were added to $25 \mathrm{~mL}$ NB medium in 50-mL Erlenmeyer flasks containing various concentrations of streptomycin $(0,0.0025$, $0.005,0.01,0.02,0.04,0.08,0.16,0.32,0.64$, or $1.28 \mu \mathrm{g} / \mathrm{mL})$. The inoculated flasks were placed on an orbital shaker $\left(28^{\circ} \mathrm{C}, 170 \mathrm{rpm}\right)$ and the density of the flasks containing 0 and $0.08 \mu \mathrm{g} / \mathrm{mL}$ streptomycin was checked at each 12-h interval. When the concentration of bacterial suspension in the control flask reached approximately $10^{8} \mathrm{CFU} / \mathrm{mL}$, the values of optical density at $600 \mathrm{~nm}\left(\mathrm{OD}_{600 \mathrm{~nm}}\right)$ of the bacterial suspensions in all flasks were measured with a nephelometer (WCY-WOG, Baoli, Beijing, China). Each treatment concentration was prepared in triplicate and the experiment was performed twice. A regression equation was derived by correlating the log of inhibitor concentration of streptomycin and the probit of inhibition percentage of the average OD value of $P$. syringae pv. actinidiae strains. The effective concentration for $50 \%$ inhibition $\left(\mathrm{EC}_{50}\right)$ of $P$. syringae $\mathrm{pv}$. actinidiae strains was calculated from the regression equation for each of the 102 strains. A histogram of $\mathrm{EC}_{50}$ values was plotted for all isolates, and the shape of the frequency distribution was analyzed by examining the $\mathrm{EC}_{50}$ histogram regarding curve shape, range, and mean values, as well as the ratio of the highest to lowest values.

\section{Data analysis}

Data from repeated experiments were combined for analysis because variances between experiments were homogeneous. All data were processed with the SIGMASTAT Statistical Software Package (SPSS Science, version 11, Chicago, IL, USA). EC $_{50}$ values were calculated from the sensitivity tests described above from the fitted regression line of the log-transformed percent inhibition values plotted against the log-transformed bactericide concentrations (Chen et al., 2012).

\section{RESULTS}

\section{Isolation and identification of $P$. syringae pv. actinidiae from different regions of Anhui Province}

A total of 102 single-colony strains were isolated for this study; 36, 12, 13, 26, and 15 strains were from Yuexi, Jinzhai, Huoshan, Qianshan, and Taihu counties, respectively (Table 
1). The overall isolation frequencies were $81.8,42.86,46.43,72.22$, and $12.20 \%$, respectively, suggesting that kiwifruit canker outbreaks were more severe in Yuexi and Qianshan than in the other sampled counties during 2012-2013. This was also consistent with our previous survey in these counties (unpublished data), as the weather conditions in these mountain areas (Yuexi and Qianshan) are favorable for kiwifruit canker epidemics.

All the generated $P$. syringae pv. actinidiae-like strains showed $100 \%$ similarity to the standard P. syringae pv. actinidiae strain and the previous published strains as determined by National Center for Biotechnology Information (NCBI) blasting against 16S rDNA sequences (Figure 1), and all strains yielded a 280-bp fragment after PCR amplification using the primers PsaF1/R2, which distinguish $P$. syringae pv. actinidiae from other bacteria found on kiwifruit (Figure 2). To confirm that the strains were P. syringae pv. actinidiae, strains were inoculated onto young A. chinensis 'Jintao' seedlings. All strains induced small angular necrotic leaf spots, similar to those seen in seedlings infected by the standard P. syringae pv. actinidiae strain, and from which $P$. syringae pv. actinidiae could readily be re-isolated. Together, these results confirmed the 102 isolates to be $P$. syringae pv. actinidiae.

Table 1. Collection and isolation of Pseudomonas syringae pv. actinidiae strains in five counties of Anhui Province from 2012 to 2013.

\begin{tabular}{lrrr}
\hline Lacation & \multicolumn{2}{c}{ Sample year } & Overall (by location) \\
\cline { 2 - 3 } & $2012^{\text {a }}$ & 2013 & \\
\hline Yuexi & $17(21)$ & $19(23)$ & $36(44)$ \\
Jinzhai & $6(15)$ & $6(13)$ & $12(28)$ \\
Huoshan & $7(16)$ & $6(12)$ & $13(28)$ \\
Qianshan & $12(22)$ & $14(14)$ & $26(36)$ \\
Taihu & $9(22)$ & $6(19)$ & $15(41)$ \\
\hline
\end{tabular}

a The number of Pseudomonas syringae pv. actinidiae strains isolated is listed and the total number of samples collected is given in parentheses.

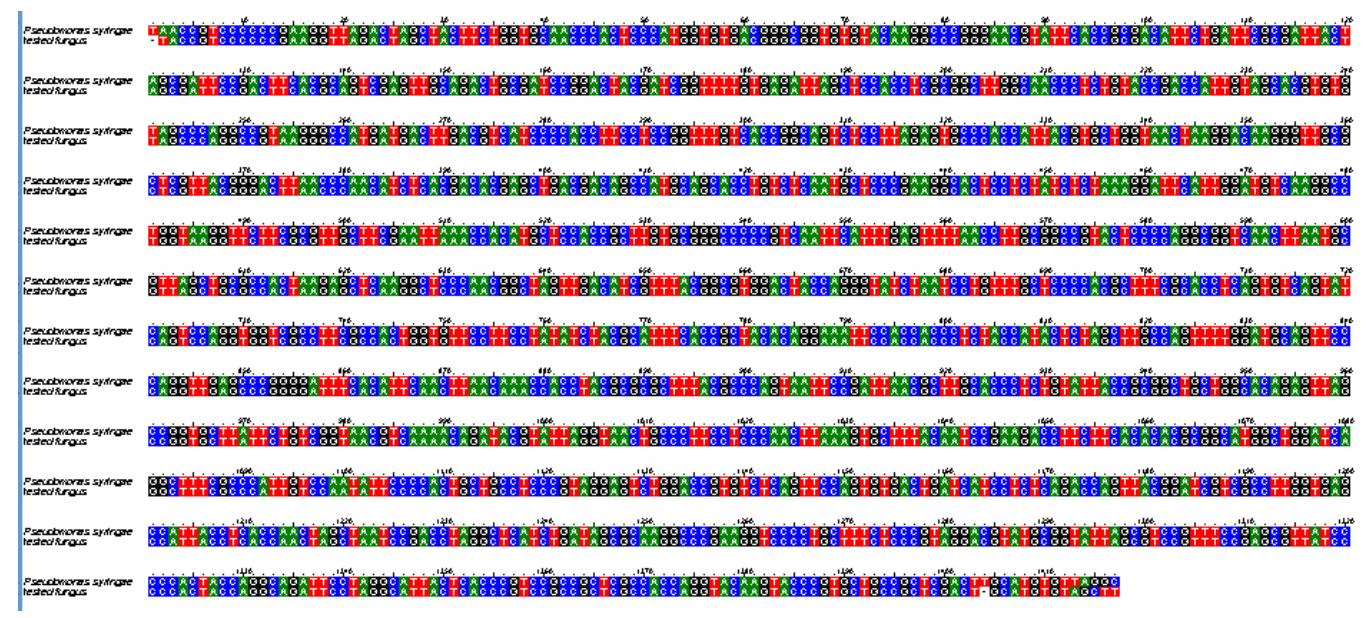

Figure 1. Similarity analysis of the isolated Pseudomonas syringae pv. actinidiae strain with previous Pseudomonas syringae pv. actinidiae strain by blasting in NCBI with the partial 16s rDNA(GenBank accession No.: JQ957916.1). 


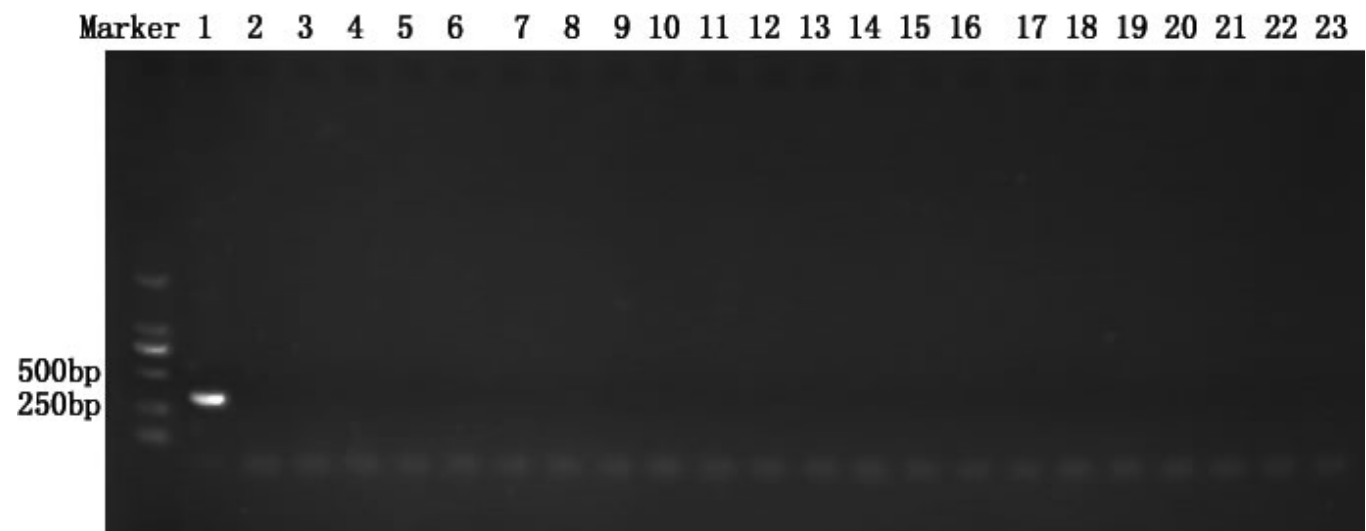

Figure 2. Specific detection of Pseudomonas syringae pv. actinidiae strain with a 280-bp fragment. Marker: DL2000; lane 1 = Pseudomonas syringae pv. actinidae; lane $2=$ Pseudomonas syringae pv. glycinea; lane $3=$ Pseudomonas syringae pv. tomato; lane $4=$ Pseudomonas aeruginosa; lane $5=$ Pseudomonas fluorescens; lane 6 $=$ Escherichia coli; lane $7=$ Bacillus subtilis; lane $8=$ Agrobacterium tumefaciens; lane $9=$ Xanthomonas oryzae pv. oryzicola; lane $10=$ Xanthomonas oryzae pv. oryzae; lane $11=$ Acidovorax avenae subsp Citrulli; lane $12=$ Corynebacterium michiganensis; lane $13=$ Pectobacterium stewartii; lane $14=$ Pectobacterium amylovora; lane $15=$ Pectobacterium carotovora; lane $16=$ Claribacter michiganense subsp Sepedonicum; lane $17=$ Liberobacter asianticum; lane $18=$ Ralstonia solanacearum; lane $19=$ Curtobacterium flaccumfaciens; lane $20=$ Agrobacterium rhizogenes; lane $21=$ Pantoca stewartii; lane $22=$ Pesudomonas syringae pv. lachrymans; lane $23=\mathrm{H}_{2} \mathrm{O}$.

\section{Baseline streptomycin sensitivity of $P$. syringae pv. actinidiae strains from Anhui Province}

The sensitivity to streptomycin of the 102 P. syringae pv. actinidiae strains isolated from Anhui Province was tested. The $\mathrm{EC}_{50}$ values for streptomycin inhibition of bacterial growth were $0.03-0.42 \mu \mathrm{g} / \mathrm{mL}$ (average $\mathrm{EC}_{50}$ value $0.12 \pm 0.06 \mu \mathrm{g} / \mathrm{mL}$ ) (Figure 3). No evidence was found for geographical variation in the sensitivity of $P$. syringae pv. actinidiae to streptomycin, and the sensitivity of the tested isolates remained unchanged from 2012 to 2013 (data not shown). The baseline sensitivity curve was unimodal (Figure 1), representing range-of-variation factors of 14.0. No resistant subpopulations were identified among the strains used in the study. Thus, these sensitivity data are suitable for use as a baseline for monitoring the shift of sensitivity of $P$. syringae pv. actinidiae populations to streptomycin in Anhui Province.

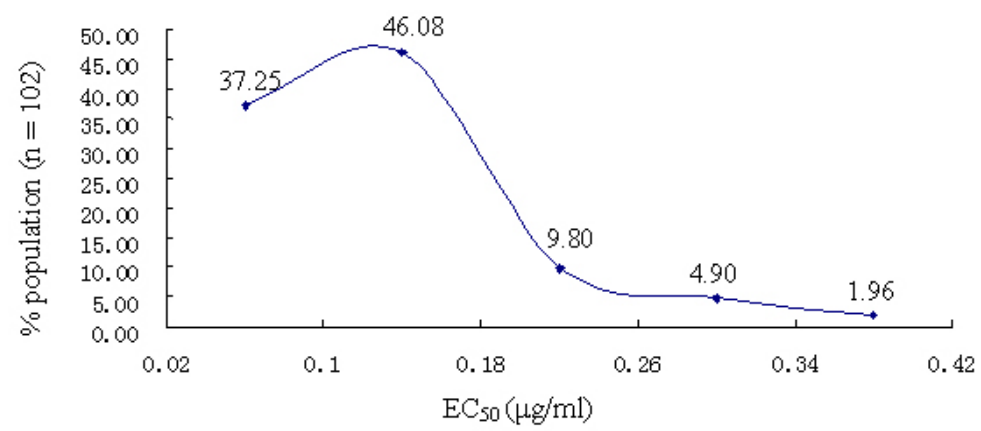

Figure 3. Frequency distribution of sensitivity (baseline sensitivity) of 102 Pseudomonas syringae pv. actinidiae strains to streptomycin. 


\section{DISCUSSION}

Kiwifruit canker is an internationally important disease, as it occurs in most of the kiwifruit-growing regions worldwide and causes severe damage to kiwifruit production. Identification of its pathogen, P. syringae pv. actinidiae, is very useful for the understanding of this disease. Specific PCR primers for one-step identification of $P$. syringae pv. actinidiae had not been provided in early studies (Sawada et al., 1997; Koh and Nou, 2002; Scortichini et al., 2002) and were not available until recently (Rees-George et al., 2010). PsaF1/R2 and PsaF3/ R4 were designed to be complementary to a portion of the 16S-23S rDNA ITS region, and were shown to amplify a DNA fragment from strains of P. syringae pv. actinidiae, but not from 56 strains of bacteria from six genera and 17 species (Rees-George et al., 2010), permitting quick identification of the pathogen isolated from kiwifruit tissues. Although PsaF1/R2 and PsaF3/R4 were able to distinguish P. syringae pv. actinidiae from other pseudomonads isolated from kiwifruit orchards, and from a number of other bacteria, these primers were not able to distinguish P. syringae pv. actinidiae from P. syringae pv. theae, a strain of the tea pathogen. However, because $P$. syringae pv. theae is unlikely to be found on kiwifruit, primers PsaF1/R2 and PsaF3/R4 are recommended for screening bacteria isolated from kiwifruit tissue.

In this study, we used the primers PsaF1/R2 for specific amplification of the 280-bp fragment from the isolated $P$. syringae pv. actinidiae-like strains from kiwifruit. As expected, each of the P. syringae pv. actinidiae-like strains yielded the 280-bp fragment. To further confirm their identity as $P$. syringae pv. actinidiae strains, we performed a pathogenicity assay to fulfill Koch's postulates. All strains caused small angular necrotic leaf spots, similar to those seen in infected orchards, and from which $P$. syringae pv. actinidiae could readily be re-isolated, suggesting that the isolated bacteria were $P$. syringae pv. actinidiae.

Chemical control remains an important tool for the control of kiwifruit canker, because most cultivars planted in Anhui Province are susceptible to this disease. Streptomycin has been the most commonly used bactericide for the control of kiwifruit canker in China for decades. To sustainably control this disease, it is necessary to establish the baseline sensitivity of $P$. syringae pv. actinidiae strains to streptomycin, which would give us an important database to understand its activity and monitor its possible sensitivity shifts after years of application. In this study, the baseline sensitivity of 102 P. syringae pv. actinidiae strains to streptomycin was established by a growth-inhibition assay. The results showed that the $\mathrm{EC}_{50}$ values for streptomycin ranged from 0.03 to $0.42 \mu \mathrm{g} / \mathrm{mL}$ and exhibited a unimodal frequency distribution. As none of these strains had ever been exposed to streptomycin, these sensitivity data could be used as baseline sensitivity measure for monitoring any future changes in sensitivity to streptomycin in P. syringae pv. actinidiae populations in the Anhui Province of China.

Taken together, these results suggest that streptomycin is an appropriate tool for the management of kiwifruit canker. Continuous resistance monitoring of $P$. syringae pv. actinidiae populations to streptomycin should be carried out since it is an at-risk bactericide (Xu et al., 2010). In addition, a mixture of streptomycin with other groups of bactericides such as copper-based bactericides (bismerthiazol, thiram, etc.) should be applied to avoid or delay the development of resistance.

In summary, this is the first report of the baseline sensitivity of $P$. syringae pv. actinidiae strains to streptomycin, providing us with an important database to understand its activity and monitor its possible sensitivity shift after additional years of application. In addition, the PCR results revealed that the primers PsaF1/R2 are suitable for specific detection of $P$. syringae pv. actinidiae. 


\section{ACKNOWLEDGMENTS}

Research supported by i) the Anhui Provincial Fruit "115" Innovation Team; ii) the Important and New Discipline Program of the Anhui Academy of Agricultural Sciences (\#12A0303); iii) the Anhui Provincial Fruit Industrial System; iv) the National Natural Science Foundation of China (\#31201550, \#31272073 and \#31301765); v) the Special Fund for Agro-Scientific Research in the Public Interest from the Ministry of Agriculture, China (\#201303015 and \#201303023); vi) the 2014 Science and Technological Fund of Anhui Province for Outstanding Youth (\#1408085J02); vii) the Discipline Construction Program of the Anhui Academy of Agricultural Sciences (\#14A1130); and viii) the Innovation Team of the Anhui Academy of Agricultural Sciences (\#12C1105, \#13C1113, and \#14C1111).

\section{REFERENCES}

Abelleira A, López MM, Peñalver J, Aguín O, et al. (2011). First report of bacterial canker of kiwifruit caused by Pseudomonas syringae pv. actinidiae in Spain. Plant Dis. 95: 1583.

Balestra GM, Mazzaglia A, Quattrucci A, Renzi M, et al. (2009). Occurrence of Pseudomonas syringae pv. actinidiae in Jin Tao kiwi plants in Italy. Phytopathol. Mediterr. 48: 299-301.

Balestra GM, Renzi M and Mazzaglia A (2010). First report of bacterial canker of Actinidia deliciosa caused by Pseudomonas syringae pv. actinidiae in Portugal. New Disease Report 22: 10.

Balestra GM, Taratufolo MC, Vinatzer BA and Mazzaglia A (2013). A multiplex PCR assay for detection of Pseudomonas syringae pv. actinidiae and differentiation of populations with different geographic origin. Plant Dis. 97: 472-478.

Bastas KK and Karakaya A (2012). First report of bacterial canker of kiwifruit caused by Pseudomonas syringae pv. actinidiae in Turkey. Plant Dis. 96: 452.

Bull CT, Clarke CR, Cai R, Vinatzer BA, et al. (2011). Multilocus sequence typing of Pseudomonas syringae sensu lato confirms previously described genomospecies and permits rapid identification of $P$. syringae pv. coriandricola and P. syringae pv. apii causing bacterial leaf spot on parsley. Phytopathology 101: 847-858.

Chapman JR, Taylor RK, Weir BS, Romberg MK, et al. (2012). Phylogenetic relationships among global populations of Pseudomonas syringae pv. actinidiae. Phytopathology 102: 1034-1044.

Chen Y, Zhang A-F, Wang W-X, Zhang Y, et al. (2012). Baseline sensitivity and efficacy of thifluzamide in Rhizoctonia solani. Ann. Appl. Biol. 161: 247-254.

EPPO (2011). First report of Pseudomonas syringae pv. actinidiae in Switzerland. EPPO Reporting Service 8; 2011/2168.

Fang Y, Zhu X and Wang Y (1990). Preliminary studies on kiwifruit diseases in Hunan Province. Sichuan Fruit Sci. Technol. 18: 28-29.

Ferrante P and Scortichini M (2009). Identification of Pseudomonas syringae pv. actinidiae as causal agent of bacterial canker of yellow kiwifruit (Actinidia chinensis Planchon) in central Italy. J. Phytopathol. 157: 768-770.

Ferrante P and Scortichini M (2010). Molecular and phenotypic features of Pseudomonas syringae pv. actinidiae isolated during recent epidemics of bacterial canker on yellow kiwifruit (Actinidia chinensis) in central Italy. Plant Pathol. 59: 954-962.

Koh JK, Cha BJ, Chung HJ and Lee DH (1994). Outbreak and spread of bacterial canker in kiwifruit. Korean J. Plant Pathol. 10: 68-72.

Koh YJ and Nou IS (2002). DNA markers for identification of Pseudomonas syringae pv. actinidiae. Mol. Cells 13: 309-314.

Li J, Zhou M, Li H, Chen C, et al. (2006). A study on the molecular mechanism of resistance to amicarthiazol in Xanthomonas campestris pv. citri. Pest Manag. Sci. 62: 440-445.

Mazzaglia A, Renzi M and Balestra GM (2011). Comparison and utilization of different PCR-based approaches for molecular typing of Pseudomonas syringae pv. actinidiae strains from Italy. Can. J. Plant Pathol. 33: 8-18.

McManus PS, Stockwell VO, Sundin GW and Jones AL (2002). Antibiotic use in plant agriculture. Annu. Rev. Phytopathol. 40: 443-465.

Rees-George J, Vanneste JL, Cornish DA, Pushparajah IPS, et al. (2010). Detection of Pseudomonas syringae pv. actinidiae using polymerase chain reaction (PCR) primers based on the 16S-23S rDNA intertranscribed spacer region and comparison with PCR primers based on other gene regions. Plant Pathol. 59: 453-464.

Russell PE (2004). Sensitivity baselines in fungicide resistance research and management. In: FRAC Monograph 3. CropLife International, Brussels. Available at [www.frac.Info]. 
Sawada H, Takeuchi T and Matsuda I (1997). Comparative analysis of Pseudomonas syringae pv. actinidiae and pv. phaseolicola based on phaseolotoxin-resistant ornithine carbamoyltransferase gene $(\arg K)$ and 16S-23S rRNA intergenic spacer sequences. Appl. Environ. Microbiol. 63: 282-288.

Scortichini M (1994). Occurrence of Pseudomonas syringae pv. actinidiae on kiwifruit in Italy. Plant Pathol. 43: 10351038.

Scortichini M, Marchesi U and Di Prospero P (2002). Genetic relatedness among Pseudomonas avellanae, P. syringae pv. theae and P. s. pv. actinidiae, and their identification. Eur. J. Plant Pathol. 108: 269-278.

Sundin GW and Bender CL (1993). Ecological and genetic analysis of copper and streptomycin resistance in Pseudomonas syringae pv. syringae. Appl. Environ. Microbiol. 59: 1018-1024.

Takikawa Y, Serizawa S, Ichikawa T, Tsuyumu S, et al. (1989). Pseudomonas syringae pv. actinidiae pv. nov.: the causal bacterium of canker of kiwifruit in Japan. Ann. Phytopathol. Soc. Japan 55: 437-444.

Vanneste JL, Poliakoff F, Audusseau C, Cornish DA, et al. (2011a). First report of Pseudomonas syringae pv. actinidiae, the causal agent of bacterial canker of kiwifruit in France. Plant Dis. 95: 1311.

Vanneste JL, Yu J, Cornish DA, Max S, et al. (2011b). Presence of Pseudomonas syringae pv. actinidiae, the causal agent of bacterial canker of kiwifruit, on symptomatic and asymptomatic tissues of kiwifruit. New Zeal. Plant Prot. 64: 241-245.

Vanneste JL, Yu J, Cornish DA, Tanner DJ, et al. (2013). Identification, virulence, and distribution of two biovars of Pseudomonas syringae pv. actinidiae in New Zealand. Plant Dis. 97: 708-719.

Xu Y, Zhu XF, Zhou MG, Kuang J, et al. (2010). Status of streptomycin resistance in Xanthomonas oryzae pv. oeyzae and Xanthomonas oryzae pv. oryzicola in China and their resistance characters. J. Phytopathol. 158: 601-608.

Zhang Y, Chen Y, Zhu X, Xu Y, et al. (2011). A molecular mechanism of resistance to streptomycin in Xanthomonas oryzae pv. oryzicola. Phytoparasitica 39: 393-401. 